\title{
Efeitos da everminação de matrizes e de bezerros lactentes em sistema de produção de bovinos de corte na região de Cerrado ${ }^{1}$
}

\author{
João B. Catto ${ }^{2}$, Ivo Bianchin ${ }^{2}$ e Roberto A.A. Torres Junior ${ }^{2}$
}

\begin{abstract}
Catto J. B., Bianchin I., Torres Junior R. A. A 2005. [Effects of deworming of cowcalf beef herds in brazilian savannas.] Efeitos da everminação de matrizes e de bezerros lactentes em sistema de produção de bovinos de corte na região de Cerrado. Pesquisa Veterinária Brasileira 25(3):188-194. Embrapa Gado de Corte, Rodov. 162, Km 4, Campo Grande, MS 79002950, Brazil.E-mail: catto@cnpgc.embrapa.br

The effect of deworming with ivermectin of cows before calving and of suckling calves on fecal egg counts (EPG) and productive performance of two beef cattle herds in Central Brazil was studied. Four groups of pregnant cows received the following treatments: T1- cows and calves not treated, T2- only calves treated, T3- only cows treated, and T4- cows and calves treated. The calves of T2 and T4 were distributed in the following treatments: A- calves treated at 3 to 5 months of age with long action ivermectin, B- treated with ivermectin, and C- control. For the cows, the deworming did not diminish the EPG during lactation and also did not have significant effect on the conception rate, live weight gain and the body weight of their calves at 3 to 5 months of age. The calves of treatment $A$ gained, from the time of treatment to weaning (84 to 108 days), an average of $4.2 \mathrm{~kg}(\mathrm{P}=0.0003)$ and $7.1 \mathrm{~kg}(\mathrm{P}<0.0001)$ more than those of treatment $\mathrm{B}$ and $\mathrm{C}$, respectively. The average difference in live weight gain of $2.9 \mathrm{~kg}$ between the animals of treatment $B$ and $C$ was not significant. The EPG before treatment was not significantly different from the treatments $(\mathrm{P}=0.8665)$; but at weaning, the average EPG of the calves from treatment $A$ was lower than for treatment $B(P=0.0004)$ and $C(P<0.0001)$. There was no significant difference in the mean EPG for the calves from treatment $B$ and $C$.
\end{abstract}

INDEX TERMS: Beef cattle, cows, suckling calves, nematodes, treatment, Brazilian savannas.

RESUMO.- Estudou-se o efeito da everminação de vacas no préparto e de bezerros antes do desmame, no número de ovos de nematódeos nas fezes (OPG) e nos parâmetros produtivos em dois rebanhos de gado de corte na região do Brasil Central. Quatro lotes de vacas prenhes receberam os seguintes tratamentos: T1- vacas e bezerros controle, T2- somente bezerros tratados, T3- somente vacas tratadas antes do parto com ivermectina e T4- vacas e bezerros tratados. Os bezerros dos lotes T2 e T4 foram distribuídos nos seguintes grupos: A- tratados aos 3 a 5 meses de idade com ivermectina de ação prolongada, B- tratados com ivermectina e C- controle. Nas vacas a everminação não diminuiu o OPG durante a lactação, como também não teve efeito significativo na taxa de concepção, no gan-

\footnotetext{
1 Recebido em 10 de agosto de 2004

Aceito para publicação em 28 de abril de 2005.

2 Embrapa Gado de Corte, BR 262 Km 4, Cx. Postal 154, Campo Grande, MS 79002-970, Brazil. *Autor para correspondência. E-mail: catto@cnpgc.embrapa.br
}

ho de peso e no peso dos bezerros aos 3 a 5 meses de idade. Os bezerros do Grupo A ganharam até o desmame, 84 a 108 dias após o tratamento, em média $4,2 \mathrm{~kg}(\mathrm{P}=0,0003)$ e $7,1 \mathrm{~kg}$ $(\mathrm{P}<0,0001)$ mais que aqueles dos Grupos $\mathrm{B}$ e $\mathrm{C}$, respectivamente. A diferença média, no ganho de peso, de $2,9 \mathrm{~kg}$ entre os bezerros dos Grupos B e C não foi significativa. Antes do tratamento não houve diferença significativa $(P=0,8665)$, mas ao desmame, o OPG médio dos bezerros do Grupo A era menor que os do Grupo B $(P=0,0004)$ e do Grupo $C(P<0,0001)$. Não houve diferença no OPG entre os bezerros dos Grupos B e C.

TERMOS DE INDEXAÇÃO: Bovino de corte, vacas, bezerros lactentes, nematódeos, tratamento, Cerrado.

\section{INTRODUÇÃO}

Diferente do que ocorre na fase de recria onde há consenso da importância da everminação, o uso de anti-helmínticos em vacas e em bezerros lactentes gera controvérsias entre parasitologistas e produtores. A everminação nessas categorias, do ponto de vista econômico, é defendida pelos que são favoráveis alegando 
que as infecções subclínicas em animais adultos ou lactentes prejudicam o desempenho, embora a resposta seja mais difícil de ser detectada. Sustentam que o efeito é deletério apoiando-se nas vantagens de performance de rebanhos de cria quando submetidos ao tratamento da verminose. Da mesma forma, os que contestam o retorno bioeconômico do uso de anti-helmínticos nessas categorias também se apoiam em resultados de pesquisa.

Os estudos sobre os prováveis benefícios do uso de vermífugos na performance de rebanhos de cria de gado de corte têm sido realizados quase que exclusivamente em países de clima frio ou temperado. Reinemeyer (1992) em uma revisão sobre o uso da everminação, em vacas ou em vacas e em bezerros, verificou que a diferença na taxa de concepção entre vacas tratadas e não tratadas variou de -7 a $+23 \%$; foi maior nos lotes tratados em 25 dos 33 estudos realizados, mas significativamente maior em apenas um. $O$ peso ao desmame de bezerros tratados variou de $-2 \mathrm{a}+22,5 \mathrm{~kg}$, e foi significativamente maior em 8 de 27 experimentos.

No Rio Grande do Sul, região de clima temperado, Pereira (1983) encontrou em vacas cruzadas o número de ovos por grama de fezes (OPG) variando entre 0 e 40; aumento no OPG no segundo mês pós-parto e sempre superior nas vacas paridas em relação as não paridas.

Na região do Cerrado brasileiro Bianchin et al. (1987) no Mato Grosso do Sul, acompanharam durante um ciclo reprodutivo o OPG de vacas Nelore de $1^{\mathrm{a}}, 2^{\mathrm{a}}$ e $3^{\mathrm{a}}$ crias. A média de OPG nos três grupos variou entre 50 e 250 . Houve tendência de aumento do OPG duas semanas após a parição e as primíparas tiveram OPG significativamente mais elevado durante todo o período experimental. Em Minas Gerais, Lima (1998) observou em vacas Nelore médias de OPG entre 100 e 200 e concluiu que as vacas foram a principal fonte de contaminação da pastagem e de infecção dos bezerros antes do desmame. No mesmo Estado também com animais da raça Nelore, Lima \& Guimarães (1992) observaram valores de OPG entre 0 e 500 e contagens mais elevadas no período entre a primeira e quarta semana pós-parto, mas não observaram diferenças entre vacas de $1^{\mathrm{a}}, 2^{\mathrm{a}}$ e $3^{\mathrm{a}}$ crias.

Na região do Pantanal, MS, Catto (1989), durante 3 anos avaliou, mensalmente, o nível de infecção pelo OPG em vacas aneloradas lactantes e pela contagem de vermes adultos em vacas vazias abatidas para consumo na propriedade. Encontrou OPG entre 0 e 200 com contagens mais elevadas durante a estação de nascimento. Nas vacas vazias o número de vermes adultos, mais alto no período mais seco, variou entre 0 e 4000 . Concluiu que as infecções nas duas categorias foram leves.

Aumont et al. (1991) nas Ilhas Guadalupe, clima tropical úmido, em pastagens nativas e com animais da raça Creole (Zebu) encontraram OPG entre 5 e 80 entre os dias -80 a +100 do parto, e maiores contagens entre os dias -20 a +40 do parto.

Estudos sobre a resposta ao uso de anti-helmínticos em rebanhos de cria de gado de corte em climas subtropicais ou tropicais é ainda mais restrito. Aumont et al. (1991) tratando mensalmente os bezerros, obtiveram ganho de peso de $+10,5 \mathrm{~kg}$ no desmame. No Pantanal, MS, Catto \& Furlong (1982), também em pastagem nativa e em sistema super-extensivo, não encontraram diferença significativa no ganho de peso entre bezerros tratados duas vezes antes do desmame e o lote controle.
O presente estudo teve como objetivos estimar o nível de infecção pelo exame de fezes e o efeito do tratamento antihelmíntico no OPG e no ganho de peso de matrizes durante a lactação, e em bezerros antes do desmame.

\section{MATERIAL E MÉTODOS}

Local do experimento. O estudo foi conduzido em duas propriedades privadas no município de Campo Grande, MS. A região tem como característica a distribuição desigual de chuvas, freqüentes e pesadas no período chuvoso e quente (outubro-abril) e escassas e leves no período seco e mais frio (maio-setembro), semelhante a cerca de $65 \%$ do território brasileiro (Honer \& Bianchin 1993). Segundo a classificação de Köppen, o clima da região situa-se na faixa de transição entre o Cfa mesotérmico úmido, sem estiagem e o subtipo AW (clima tropical de savana) com estação chuvosa no verão e seca no inverno. A temperatura média nos meses mais frios é superior a $17^{\circ} \mathrm{C}$ e nos meses mais quentes em torno de $25^{\circ} \mathrm{C}$ (Bianchin et al. 1993).

Delineamento experimental. Um total de 910 matrizes e 933 bezerros de ambos os sexos com pelo menos 3 meses de idade foram incluídos no estudo conduzido em três ciclos pecuários sucessivos em duas propriedades (1999-2003).

Propriedade 1- rebanho de 300 matrizes Brangus, inseminadas com sêmen da mesma raça, mantidas em pastejo rotacionado com período de pastejo de 7 a 10 dias, em cinco invernadas de 90 hectares, sendo duas de Brachiaria decumbens e três de Brachiaria brizantha. Propriedade 2- Ano 1: rebanho de 250 matrizes com diferentes graus de sangue Nelore/Canchin, inseminadas com semen da raça Canchin em pastejo rotacionado em cinco invernadas de 40 hectares de Brachiara humidicola- Ano 2: rebanho de 250 vacas Nelore mantidas em pastejo rotacionado sem período fixo de pastejo em 6 invernadas de 50 hectares de $B$. humidicola, e inseminadas com semen de raça Nelore. As variáveis estudadas e avaliadas quanto ao efeito da everminação por propriedade, por ano e por categoria animal estão relacionadas no Quadro 1.

Entre julho e setembro de cada ano, antes da parição, na sequiência da pesagem, independente de idade, número de cria e escore corporal as vacas foram alocadas nos seguintes tratamentos: T1- não tratadas, T2- somente bezerros tratados, T3- somente vacas tratadas e T4vacas e bezerros tratados. Nessa ocasião e em dezembro e fevereiro coletou-se fezes para contagem do OPG. No desmame (maio/junho) foram novamente pesadas e coletaram-se fezes para OPG. O tratamento das vacas consistiu na aplicação subcutânea de ivermectina a $1 \%$, na dose de $1 \mathrm{ml} / 50 \mathrm{~kg} /$ peso do animal.

Em fevereiro/março nos dois primeiros ciclos na Propriedade $1 \mathrm{e}$ no primeiro ciclo da Propriedade 2 (Quadro 1), os bezerros com 3 a 5 meses de idade foram pesados e aqueles nascidos nos tratamentos T2 e T4, foram dentro de sexo distribuídos em três grupos: A- tratados com ivermectina de ação prolongada a $3,15 \%$, por via subcutânea, na dose de $1 \mathrm{ml} / 50 \mathrm{~kg}$, B- tratados com ivermectina a $1 \%$, na dose de

Quadro 1. Variáveis avaliadas em vacas e bezerros em cada ano e em cada propriedade

\begin{tabular}{|c|c|c|c|c|c|c|}
\hline \multirow[t]{2}{*}{ Propriedade } & \multirow[t]{2}{*}{ Ano } & \multicolumn{3}{|c|}{ Vacas } & \multicolumn{2}{|c|}{ Bezerros } \\
\hline & & OPG & Peso & Natalidade & OPG & Peso \\
\hline 1 & $2000 / 01$ & $\mathrm{X}$ & $\mathrm{X}$ & $\mathrm{X}$ & $\mathrm{X}$ & $\mathrm{X}$ \\
\hline 1 & $2001 / 02$ & $\mathrm{X}$ & $\mathrm{X}$ & $\mathrm{X}$ & $\mathrm{X}$ & $X$ \\
\hline 1 & $2002 / 03$ & - & - & - & $\mathrm{X}$ & $\mathrm{X}$ \\
\hline 2 & $2000 / 01$ & $\mathrm{X}$ & $\mathrm{X}$ & - & $\mathrm{X}$ & $\mathrm{X}$ \\
\hline 2 & $2001 / / 02$ & - & - & - & $X$ & $X$ \\
\hline
\end{tabular}


Quadro 2. Médias e erros-padrão de OPG em vacas durante a lactação, em dois sistemas de produção de bovinos de corte no município de Campo Grande, MS

\begin{tabular}{cccccc}
\hline \multirow{2}{*}{$\begin{array}{c}\text { Propriedade } \\
\text { (ano) }\end{array}$} & Tratamento & \multicolumn{4}{c}{ Período } \\
\cline { 3 - 6 } & & ago/set $^{1}$ & dez/jan & fev/mar & mai/jun $^{1}$ \\
\hline \multirow{2}{*}{1 (ano 1) } & Tratadas & $58(10,5)$ & $19(7,3)$ & $35(6,2)$ & $240(38,5)$ \\
& Controle & $54(15,1)$ & $13(4,3)$ & $50(13,2)$ & $152(25,8)$ \\
\multirow{2}{*}{ (ano 2) } & Tratadas & $11(3,3)$ & $57(29,2)$ & $214(36,7)$ & $61(19,5)$ \\
& Controle & $53(21,8)$ & $40(11,3)$ & $169(36,9)$ & $52(28,7)$ \\
2 (ano 1) & Tratadas & $10(3,2)$ & $155(23,4)$ & $322(81,7)$ & $98(30,8)$ \\
& Controle & $10(3,3)$ & $147(32,4)$ & $288(35,9)$ & $127(48,7)$ \\
Média geral & Tratadas & $37(4,0)^{\mathrm{a}}$ & $53(13,1)^{\mathrm{b}}$ & $132(22,7)^{\mathrm{c}}$ & $124(20,2)^{\mathrm{d}}$ \\
Média geral & Controle & $26(8,3)^{\mathrm{a}}$ & $70(10,1)^{\mathrm{b}}$ & $138(16,8)^{\mathrm{c}}$ & $143(19,8)^{\mathrm{d}}$
\end{tabular}

${ }^{1}$ Peri-parto, ${ }^{2}$ desmame; médias na mesma coluna com a mesma letra não diferem entre si pelo teste $\mathrm{F}(\mathrm{P}>0,05)$.

$1 \mathrm{ml} / 50 \mathrm{~kg}$ e C- controle. No desmame (maio/junho) foram novamente pesados. Fezes para OPG foram coletadas em ambas as ocasiões.

No terceiro ciclo na Propriedade 1 e no segundo ciclo na Propriedade 2, somente os bezerros foram avaliados. No mesmo período (fevereiro/março) e, na sequiência de pesagem, os bezerros foram dentro de sexo distribuídos nos Tratamentos A, B e C como nos ciclos anteriores. Fezes para o OPG foram coletadas na pesagem inicial e no desmame, ocasião em que foram novamente pesados. $\mathrm{O}$ número de amostras de fezes nas vacas e nos bezerros variou entre 30 e $90 \%$ e entre 45 e $80 \%$, respectivamente, em cada tratamento e em todas as coletas realizadas. O OPG foi feito segundo Gordon \& Whitlock (1939) utilizando-se câmara de McMaster com sensibilidade para 50 ovos por grama de fezes.

Análise dos dados. Para análise do OPG das vacas e dos bezerros, os resultados foram transformados em log decimal de $\mathrm{OPG}+1$. Inicialmente analisaram-se diferenças no OPG (nas 4 coletas realizadas), no peso inicial e no ganho de peso entre os grupos de vacas controle (T1/T2) e tratadas (T3/T4). $\mathrm{O}$ efeito do tratamento das vacas no pré-parto sobre o peso dos bezerros aos 3 a 5 meses foi realizado comparando-se o peso dos bezerros filhos das vacas controle com o peso dos bezerros das vacas tratadas. Como não houve efeito significativo do tratamento anti-helmíntico no ganho de peso e no OPG das vacas, e também não no peso dos bezerros aos 3 a 5 meses de idade, na análise do efeito da everminação no ganho de peso e no OPG dos bezerros os mesmos foram agrupados nos tratamentos independentemente do tratamento das matrizes.

No primeiro ano na Propriedade 2 durante vários meses ocorreram surtos de diarréia de causa(s) não identificada(s) provocando a morte de vários animais e o comprometimento do desenvolvimento ponderal de todos os bezerros nascidos nesse ano, mascarando um possível efeito do tratamento anti-helmíntico. Os resultados observados nessa

Quadro 3. Médias e erros-padrão do peso inicial e da perda de peso em vacas durante a lactação em dois sistemas de produção de bovinos de corte no município de Campo Grande, MS

\begin{tabular}{|c|c|c|c|c|c|c|c|c|}
\hline \multirow{2}{*}{$\begin{array}{c}\text { Propriedade } \\
\text { (ano) }\end{array}$} & \multicolumn{4}{|c|}{ Peso inicial } & \multicolumn{4}{|c|}{ Perda de peso } \\
\hline & $\mathrm{n}$ & Controle & $\mathrm{n}$ & Tratadas & $\mathrm{n}$ & Controle & $\mathrm{n}$ & Tratadas \\
\hline 1 (ano 1) & 126 & $459(5,9)$ & 128 & $456(6,2)$ & 126 & $-34,8(3,1)$ & 128 & $-35,1(3,1)$ \\
\hline 1 (ar & 144 & $473(5,0)$ & 142 & $473(4,8)$ & 144 & $-30,0(3,4)$ & 142 & $-30,5(3,4)$ \\
\hline 2 (ano 1) & 90 & $336(5,3)$ & 97 & $336(4,5)$ & 90 & $-7,7(3,8)$ & 97 & $-10,7(3,3)$ \\
\hline Média geral & & $407(3,9)^{\mathrm{a}}$ & & $404(3,9)^{\mathrm{a}}$ & & $-26,2(2,0)^{b}$ & & $-26,5(1,9)^{b}$ \\
\hline
\end{tabular}

Médias na mesma linha para peso inicial e perda de peso com letras iguais não diferem entre si pelo teste $\mathrm{F}(\mathrm{P}>0,05)$. propriedade, nesse ano, estão sendo apresentados com o intuito de alertar sobre a importância dessa enfermidade no desenvolvimento dos bezerros, mas não foram considerados nas análises estatísticas.

$\mathrm{O} \mathrm{OPG}$, o peso inicial e o ganho de peso, foram submetidos à análise de variância considerando a combinação fazenda/ano como bloco além dos efeitos de tratamento e sexo.

Todas as análises estatísticas foram feitas usando o procedimento GLM (General Linear Models) do SAS (1991) e quando necessário foi utilizado o teste de Tukey para comparar médias entre tratamentos. Valor de P de 0,05 ou menor foi considerado significativo.

\section{RESULTADOS}

A média de OPG nas vacas variou entre 10 e 322, e, independente de tratamento, mostrou tendência a aumentar entre o préparto e o desmame. Na Propriedade 1, as médias mais elevadas foram ao desmame e na metade posterior do período de lactação no primeiro e segundo ano, respectivamente. Na Propriedade 2 as médias de OPG foram mais elevadas também na metade final da fase da lactação (Quadro 2). Não houve diferença significativa entre as médias de OPG dos grupos tratado e controle nas quatro coletas realizadas. Nas coletas de agosto/setembro e dezembro/janeiro, 10 a $50 \%$ das vacas estavam positivas, enquanto que 70 a $100 \%$ das vacas estavam positivas nas coletas de fevereiro/março e maio/junho. $\mathrm{O}$ efeito bloco propriedade/ano foi significativo $(\mathrm{P}<0,0001)$, mas não houve diferença significativa no OPG das vacas controle e tratadas $(\mathrm{P}>0,05)$ nas quatro coletas realizadas.

Nos três ciclos estudados as matrizes perderam peso entre o parto e o desmame (Quadro 3). O efeito bloco, propriedade/ano, foi significativo tanto para peso inicial como para perda de peso $(\mathrm{P}<0,0001)$, mas não houve diferença significativa na perda de peso entre os lotes controle e tratado. Da mesma forma, nos dois ciclos estudados na Propriedade 1 não se observou diferença na taxa de natalidade (Quadro 4). Também não houve efeito significativo do tratamento das vacas no peso dos bezerros aos 3 a 5 meses de idade (Quadro 5). Nos dois ciclos analisados as bezerras e bezerros oriundos das vacas tratadas estavam em média com $-3,4$ e $-6,7 \mathrm{~kg}$ que as bezerras e bezerros filhas das vacas controle, respectivamente. A análise estatística dos dados da Propriedade 1, Ano 1, corrigindo o peso dos bezerros para data e peso ao nascimento, também não mostrou diferença significativa entre tratamentos (Quadro 5).

Na primeira coleta aos 3 a 5 meses de idade, antes do tratamento, uma percentagem elevada (70-99\%) dos bezerros estavam parasitados com OPG médio entre 158 e 410 em ambas as propriedades. No desmame, 84 a 108 dias após inicio do experimento 52 a $84 \%$ dos bezerros do Grupo A, 60 a 96\% do Grupo B e 85 a $100 \%$ do Controle estavam parasitados com médias de

\section{Quadro 4. Percentagens de prenhez em vacas tratadas e não tratadas com anti-helmínticos no início da parição na Propriedade 1}

\begin{tabular}{cccccc}
\hline Ano & Categoria & N & Prenhes & Vazia & Prenhez (\%) \\
\hline \multirow{2}{*}{1} & Tratadas & 128 & 89 & 39 & 69,5 \\
& Controle & 125 & 88 & 37 & 70,4 \\
2 & Tratadas & 161 & 121 & 40 & 75,1 \\
& Controle & 162 & 120 & 42 & 74,0
\end{tabular}


Quadro 5. Médias e erros-padrão do peso de bezerros aos 3 a 5 meses de idade, filhos de matrizes controle e tratadas com anti-helmíntico no periparto, em duas propriedades no município de Campo Grande, MS

\begin{tabular}{ccccc}
\hline \multirow{2}{*}{$\begin{array}{c}\text { Tratamento vacas } \\
\text { (ano) }\end{array}$} & $\mathrm{n}$ & Machos & $\mathrm{n}$ & Fêmeas \\
\cline { 2 - 5 } & 68 & $134,5(4,1)$ & 42 & $127,6(5,0)$ \\
Controle (ano 1) & 68 & $150,4(3,9)$ & 65 & $138,7(3,8)$ \\
Controle (ano 2) & 57 & $132,2(5,0)$ & 64 & $123,2(4,7)$ \\
Tratadas (ano 1) & 64 & $139,0(3,7)$ & 71 & $137,4(3,1)$ \\
Tratadas (ano 2) & & $142,5(2,9)^{\mathrm{a}}$ & & $134,1(3,0)^{\mathrm{b}}$ \\
Média geral de controle & & $135,8(3,0)^{\mathrm{a}}$ & & $130,7(2,8)^{\mathrm{b}}$ \\
Média geral de tratada & & & \\
Peso corrigido 120 dias & 58 & $122,9(2,5)^{\mathrm{c}}$ & 33 & $116,3(3,3)^{\mathrm{d}}$ \\
Controle (ano 1) & 52 & $123,2(3,3)^{\mathrm{c}}$ & 55 & $112,7(2,7)^{\mathrm{d}}$
\end{tabular}

Médias seguidas de mesma letra na mesma coluna não diferem entre si pelo teste $\mathrm{F}(\mathrm{P}>0,05)$. tiva entre tratamentos $(P=0,8665)$, mas no desmame os bezerros do Grupo A estavam com OPG significativamente menor que os do Grupo B $(\mathrm{P}=0,0004)$ e que os do Grupo C $(\mathrm{P}<0,0001)$ (Quadro 6).

Com exceção do Ano 1, na Propriedade 2, em que a média de ganho de peso vivo diário foi de 200 a $300 \mathrm{~g}$ causado por surtos de diarréia nessa propriedade, nos demais ciclos a média de ganho de peso dos animais variou entre 530 e $820 \mathrm{~g} / \mathrm{dia}$. De modo geral, em todos os anos, tanto nos machos como nas fêmeas, houve tendência dos animais do Grupo A ganharem mais peso que os animais controle, e os animais do Grupo B com ganhos intermediários (Quadro 8). Na média dos três anos avaliados os machos do Grupo A ganharam $6,8 \mathrm{~kg}$ e os do Grupo B $3,8 \mathrm{~kg}$ a mais que os machos do Grupo $\mathrm{C}$, enquanto que as fêmeas ganharam $6,9 \mathrm{~kg}$ e $4,6 \mathrm{~kg}$, a mais que as fêmeas do Grupo Controle, respectivamente. $\mathrm{O}$ surto de diarréia na Propriedade

Quadro 6. Médias aritméticas e erros-padrão do OPG em bezerros aos 3 a 5 meses de idade e ao desmame submetidos à três tratamentos em dois sistemas de produção de bovinos de corte no município de Campo Grande, MS

\begin{tabular}{|c|c|c|c|c|c|c|}
\hline \multirow{3}{*}{$\begin{array}{l}\text { Propriedade } \\
\text { (ano) }\end{array}$} & \multicolumn{6}{|c|}{ Tratamentos } \\
\hline & A & B & $\mathrm{C}$ & $\mathrm{A}$ & B & $\mathrm{C}$ \\
\hline & \multicolumn{3}{|c|}{ Idade 3 a 5 meses } & \multicolumn{3}{|c|}{ Idade desmame } \\
\hline 1 (ano 1) & $173(42,2)$ & $217(42,7)$ & $158(18,7)$ & $113(22,6)$ & $270(54,0)$ & $414(42,1)$ \\
\hline 1 (ano 2) & $233(66,7)$ & $330(80,3)$ & $207(38,0)$ & $289(58,7)$ & $362(54,3)$ & $552(104,8)$ \\
\hline 1 (ano 3) & $168(34,1)$ & $161(35,0)$ & $203(47,3)$ & $245(53,6)$ & $218(41,3)$ & $282(57,7)$ \\
\hline 2 (ano 1) & $381(72,6)$ & $347(47,2)$ & $410(82,7)$ & $81(14,5)$ & $140(23,3)$ & $294(33,1)$ \\
\hline 2 (ano 2) & $377(52,3)$ & $312(38,9)$ & $342(58,1)$ & $290(69,0)$ & $569(100,4)$ & $538(62,2)$ \\
\hline Média geral & $240(23,3)^{a}$ & $246(21,2)^{a}$ & $229(20,5)^{\mathrm{a}}$ & $190(25,3)^{\mathrm{a}}$ & $280(31,9)^{b}$ & $364(28,7)^{b}$ \\
\hline
\end{tabular}

Médias na mesma linha, em cada idade, com letras diferentes diferem entre si pelo teste $\mathrm{F}$ ( $\mathrm{P}<$ 0,05); A- ivermectina LA; B- ivermectina; C- controle. Dados da Propriedade 2, Ano 1, não incluídos na média geral e na análise estatística.

Quadro 7. Prevalência (\%) de bezerros positivos para nematódeos (OPG) aos 3 a 5 meses de idade e ao desmame, tratados e controle, em dois sistemas de produção de bovinos de corte no município de Campo Grande, MS

\begin{tabular}{|c|c|c|c|c|c|c|}
\hline Propriedade/ & \multicolumn{2}{|c|}{ Ano 1} & \multicolumn{2}{|c|}{ Ano 2} & \multicolumn{2}{|c|}{ Ano 3} \\
\hline Tratamento 1 & 3 a 5 meses & Desmame & 3 a 5 meses & Desmame & 3 a 5 meses & Desmame \\
\hline $1 / \mathrm{A}$ & 77 & 52 & 75 & 84 & 72 & 60 \\
\hline $1 / \mathrm{B}$ & 90 & 79 & 70 & 85 & 77 & 82 \\
\hline $1 / C$ & 85 & 85 & 83 & 88 & 79 & 85 \\
\hline $2 / A$ & 80 & 77 & 100 & 80 & & \\
\hline $2 / \mathrm{B}$ & 78 & 60 & 97 & 96 & & \\
\hline $2 / C$ & 99 & 97 & 90 & 100 & & \\
\hline
\end{tabular}

${ }^{1} \mathrm{~A}$ - ivermectina LA, B- ivermectina, C- controle.

OPG de 81 a 290, 140 a 569 e 282 a 552, respectivamente (Quadros 6 e 7).

Nos animais controle, conforme esperado, as médias foram sempre maiores no desmame, exceto no Ano 1 na Propriedade 2. Nessa fazenda, no primeiro ano, ocorreram fortes surtos de diarréia (causa não diagnosticada) durante os primeiros meses de vida dos bezerros tornando-os mais susceptíveis às infecções por nematódeos. Na coleta inicial não houve diferença significa-
2, no primeiro ano, além de diminuir o ganho de peso de todos, provavelmente, também anulou diferenças no ganho de peso que o tratamento anti-helmíntico poderia proporcionar. No entanto, os resultados não foram constantes ao longo dos anos em ambas as propriedades. Na Propriedade 1, machos e fêmeas do Grupo A sempre ganharam mais peso que os machos (1 a 6,3 kg) e que as fêmeas ( 2,5 a 9,7kg) do Grupo Controle, respectivamente. Na Propriedade 2, no segundo ano, os machos do Grupo A 


\section{Quadro 8. Médias e erros-padrão do ganho de peso em bezerros lactentes entre 3 a 5 meses de idade e ao desmame em dois sistemas de produção de bovinos de corte no município de} Campo Grande, MS

\begin{tabular}{|c|c|c|c|c|c|c|c|c|c|c|c|}
\hline \multirow[t]{2}{*}{ Propriedade } & \multirow[t]{2}{*}{ Ano } & \multicolumn{5}{|c|}{ Ganho de peso $(\mathrm{kg})$} & & \multicolumn{4}{|c|}{ Ganho de peso/dia (g) } \\
\hline & & $\mathrm{N}$ & A & $\mathrm{N}$ & B & $\mathrm{N}$ & $\mathrm{C}$ & A & B & $\mathrm{C}$ & $\mathrm{Z}$ \\
\hline \multicolumn{12}{|l|}{ FÊMEAS } \\
\hline 1 & $2000 / 01$ & 37 & $58,8(2,3)$ & 32 & $51,9(3,0)$ & 59 & $56,3(1,8)$ & 700 & 618 & 670 & 84 \\
\hline 1 & $2001 / 02$ & 26 & $48,9(1,6)$ & 34 & $44,5(1,7)$ & 74 & $45,8(1,5)$ & 582 & 530 & 545 & 84 \\
\hline 1 & $2002 / 03$ & 39 & $78,5(1,2)$ & 40 & $72,1(2,1)$ & 39 & $68,8(1,8))$ & 727 & 668 & 637 & 108 \\
\hline 2 & $2000 / 01$ & 22 & $22,6(2,0)$ & 22 & $25,6(1,8)$ & 38 & $22,9(1,7)$ & 251 & 284 & 254 & 90 \\
\hline 2 & $2001 / 02$ & 25 & $51,0(1,7)$ & 27 & $54,9(1,6)$ & 22 & $52,6(2,2)$ & 586 & 631 & 605 & 87 \\
\hline Média geral & & & $61,3(1,2)^{\mathrm{a}}$ & & $56,7(1,4)^{\mathrm{b}}$ & & $54,4(1,0)^{\mathrm{b}}$ & 661 & 613 & 608 & \\
\hline \multicolumn{12}{|l|}{ MACHOS } \\
\hline 1 & $2000 / 01$ & 41 & $68,8(2,2)$ & 40 & $64,0(2,5)$ & 52 & $62,5(1,9)$ & 819 & 762 & 744 & 84 \\
\hline 1 & $2001 / 02$ & 40 & $48,8(1,6)$ & 33 & $45,7(2,0)$ & 58 & $45,3(1,3)$ & 581 & 544 & 539 & 84 \\
\hline 1 & $2002 / 03$ & 45 & $77,9(2,0)$ & 45 & $74,5(2,0)$ & 39 & $76,9(1,6)$ & 721 & 690 & 712 & 108 \\
\hline 2 & $2000 / 01$ & 13 & $19,9(2,5)$ & 14 & $19,8(2,1)$ & 25 & $18,5(1,6)$ & 221 & 220 & 206 & 90 \\
\hline 2 & $2001 / 02$ & 31 & $62,3(1,6)$ & 30 & $55,1(1,4)$ & 25 & $50,6(1,6$ & 716 & 633 & 582 & 87 \\
\hline Média geral & & & $65,0(1,3)^{a}$ & & $61,2(1,3)^{b}$ & & $58,2(1,2)^{b}$ & 710 & 665 & 645 & \\
\hline
\end{tabular}

A- ivermectina LA, B- ivermectina, C- controle, $\mathrm{Z}$ - intervalo em dias entre o tratamento e o desmame. Letras diferentes na mesma linha diferem entre si pelo teste $\mathrm{F}(\mathrm{P}<0,05)$; dados da Propriedade 2 , no Ano 1 , não computados para cálculo da média geral e não utilizados na análise estatística. $\mathrm{N}=$ tamanho da amostra.

ganharam em média $11,7 \mathrm{~kg}$ a mais que os do Grupo Controle. As fêmeas, no entanto, perderam $1,6 \mathrm{~kg}$.

Independente de sexo os animais do Grupo A ganharam até o desmame (84-108 dias após o tratamento) em média $4,2 \mathrm{~kg}$ $(\mathrm{P}=0,0003)$ e $7,1 \mathrm{~kg}(\mathrm{P}<0,0001)$ mais que aqueles dos Grupos $\mathrm{B}$ e $\mathrm{C}$, respectivamente. A diferença média, no ganho de peso, de $2,9 \mathrm{~kg}$ entre os animais dos Grupos B e C não foi significativa. Os machos independente de tratamento ganharam em média $4,5 \mathrm{~kg}$ a mais que as fêmeas $(\mathrm{P}<0,0001)$, mas a interação sexo e tratamento não foi significativa $(\mathrm{P}=0,6926)$.

\section{DISCUSSÃO}

\section{OPG, peso e natalidade nas vacas}

A variação do OPG entre 10 e 300 observado neste estudo, em vacas de raças de clima temperado ou suas cruzas (Quadro 1) são semelhantes aos observados nos trabalhos anteriores realizados no Brasil com bovinos da raça Nelore (Bianchin et al. 1987, Catto 1989, Lima \& Guimarães 1992), mas superiores aos encontrados em 11 estudos realizados na América do Norte, com média de OPG entre 1,2 e 115 (Reinemeyer 1992).

$\mathrm{O}$ aumento do OPG no peri-parto é um fenômeno conhecido em ovinos e suínos e tem sido também observado em bovinos (Pereira 1983, Bianchin et al. 1987, Aumont et al. 1991, Lima \& Guimarães, 1992). Diferente do observado nesses estudos onde o OPG aumentou no peri-parto, as médias de OPG, independente de tratamento, foram maiores de meados ao final do período de lactação em ambas as propriedades (Quadro 2). A percentagem de vacas parasitadas também foram maiores de meados ao final da lactação. Nas coletas de agosto/setembro e dezembro/janeiro de 10 a $50 \%$ das vacas estavam positivas enquanto que 70 a $100 \%$ estavam positivas nas coletas de fevereiro/março e maio/ junho.

Um dos motivos da preconização do tratamento antihelmíntico das vacas no peri-parto é para evitar a contaminação das pastagens e, consequentemente, diminuir a infecção nos bezerros até o desmame (Bianchin et al. 1987, Lima \& Guimarães 1992, Lima 1998). Considerando a quantidade de massa fecal produzida e o OPG encontrado neste trabalho, e em estudos anteriores no Brasil, as vacas durante todo o período que antecede o parto até o desmame dos bezerros têm potencial muito elevado para contaminar as pastagens. Pereira (1983) concluiu que o tratamento das vacas antes (30 ou 60 dias) e depois (30 dias) do parto seria ideal para diminuir a infecção nos bezerros. No entanto, em criações de gado de corte o manejo de número elevado de animais durante a estação de nascimento é pouco prático.

Bianchin et al. (1987) verificaram que nas vacas de primeira cria, pela idade e estresse do primeiro parto, o OPG é maior do que nas de segunda e terceira cria. Devido a esse fato, as vacas de primeira cria merecem mais atenção no controle da verminose no peri-parto.

A ausência do efeito do tratamento anti-helmíntico no OPG das vacas na primeira coleta pós-tratamento, dezembro/janeiro, (Quadro 2) é decorrente, provavelmente, do longo período entre os eventos, associado ao fato dos animais compartilharem a mesma invernada, proporcionando reinfecções em níveis elevados. De modo geral, diferenças no OPG têm sido observadas somente quando vacas tratadas e controle são mantidos em pastagens separadas ou diferenças por curto período quando mantidas na mesma invernada (Ward et al. 1991).

Nos 3 anos em que avaliou-se o efeito da everminação no ganho de peso das vacas, não houve diferenças entre os grupos de vacas tratadas e controle (Quadro 3). Como as pesagens foram realizadas somente no pré-parto e ao desmame, uma possível vantagem com a aplicação do anti-helmíntico pode ter sido perdida ao longo do tempo. Diferença positiva ou negativa entre peso de vacas em razão de tratamentos anti-helmínticos deve ser interpretada com muita cautela. $O$ peso do animal, nessa 
categoria, é influenciado por muitas variáveis, como tempo de gestação e lactação. De 12 trabalhos revisados por Reinemeyer (1992), em 50\% deles as vacas tratadas ganharam mais peso que as controle e em apenas um a diferença foi estatisticamente significativa $(\mathrm{P}<0,05)$. Trabalhos mais recentes continuam a produzir resultados discordantes; ou têm encontrado diferenças significativas apenas no início do período experimental (Suarez et al. 1992), não encontrado diferenças (Ward et al. 1991) ou mesmo ganho de peso significativamente menor em relação ao grupo controle (Stromberg et al. 1977).

Como no ganho de peso, também não houve diferença na taxa de concepção entre o grupo tratado e controle, avaliados apenas nos dois primeiros ciclos na Propriedade 1. Reinemeyer (1992) na revisão sobre o uso da everminação em vacas ou em vacas e em bezerros sobre a performance do rebanho verificou que a diferença na taxa de concepção entre vacas tratadas e não tratadas variou de -7 a $+23 \%$. Foi maior, nos lotes tratados, em 25 dos 33 estudos realizados, mas significativamente maior em apenas um. Em dois estudos mais recentes em que essa variável foi avaliada (Ward et al. 1991, Stromberg et al. 1997), no primeiro não houve diferença e no segundo houve um incremento de $12 \%$ na natalidade, apesar das vacas tratadas terem tidas ganho de peso significativamente menor que as controle.

\section{Tratamento das vacas - peso dos bezerros}

Diferença significativa $(\mathrm{P}<0,05)$ sobre o peso dos bezerros ao desmame em razão da everminação das matrizes foi observada em apenas dois de sete trabalhos revisados por Reinemeyer (1992) e nenhum outro trabalho tem sido publicado após essa revisão. Nos dois ciclos avaliados o tratamento das matrizes não teve efeito significativo no peso dos bezerros aos 3 a 5 meses de idade (Quadro 5). No Brasil, Pereira (1983) também não encontrou diferença significativa entre peso de bezerros de vacas não medicadas com o peso de bezerros de vacas medicadas 60 ou 30 dias antes do parto e 30 dias pós-parto, todas mantidas na mesma invernada. Além do compartilhamento de invernada outra falha que Reinemeyer (1992) cita como possível de mascarar o efeito do tratamento das matrizes no peso de bezerros é a não correção do peso para uma determinada idade. Embora somente no primeiro ano, na Propriedade 1, tenham sido coletadas as informações que permitiram corrigir o peso dos animais para 120 dias de idade, verifica-se em razão da forma aleatória com que foram formados os grupos e o número alto de repetições em cada tratamento, uma boa consistência entre as médias de peso corrigidos e não corrigidos na Propriedade 1 (Quadro 5).

\section{Tratamento de bezerros}

O tamanho da amostra é fundamental para demonstrar diferenças modestas, mas clinicamente importantes, em parâmetros que tem grande variação inerente, como as infecções por nematódeos. O pastejo compartilhado de grupos controle com tratados, expondo os animais de ambos os grupos a níveis idênticos de infecção, potencialmente subestimando o efeito da everminação, e a ausência de repetições de tratamentos são as falhas de delineamento mais comuns nos experimentos de everminação de vacas ou de vacas/bezerros (Reinemeyer 1992). Nas estações experimentais as dificuldades são de área e de ani- mais experimentais que permitam repetições de tratamentos e de piquetes. Por outro lado, em sistemas reais onde não há restrições de animais, dificilmente há condições de repetir tratamentos em piquetes de pastagens semelhantes, além da impossibilidade de coletas (peso, fezes, necropsias) com a freqüência necessária para inferir sobre o efeito de tratamento nos parâmetros avaliados.

Na revisão de 20 experimentos, Reinemeyer (1992) encontrou seis ensaios em que o tratamento de bezerros significativamente aumentou o ganho de peso $(7-22,5 \mathrm{~kg})(\mathrm{P}<0,05)$ em animais tratados antes do desmame, não mencionando se os lotes tratados e controle compartilharam ou não o mesmo pasto. Mais recentemente de seis trabalhos publicados sobre o assunto em cinco houve efeito significativo. De comum nesses trabalhos os animais ficaram em invernadas separadas e receberam um tratamento ou tratamentos mensais de anti-helmíntico (Aumont et al. 1991, Suarez et al. 1992, Stromberg et al. 1997, Ballweber et al. 2000, Forbes et al. 2002), com exceção no trabalho de Forbes et al. (2002) em que os lotes tratados e controle compartilharam a mesma invernada, mas nesse caso o tratamento foi com um sistema de liberação lenta de ivermectina. No ensaio em que não houve efeito de tratamento (Ward et al. 1991) os animais tratados e controles compartilharam a mesma invernada.

No presente trabalho os bezerros machos tratados com uma ivermectina de ação prolongada ganharam de 2,5 a $11,7 \mathrm{~kg}$ (média de $6,8 \mathrm{~kg}$ ) e as fềmeas de -1,6 a 9,7 kg (média de $6,5 \mathrm{~kg}$ ) a mais que os do controle, correspondendo a $\pm 13 \%$ do ganho de peso obtido pelos animais entre o tratamento e o desmame (Quadro 8). Forbes et al. (2002), em cinco anos de observação encontraram nos machos uma variação no ganho de peso de 2,8 a $16,1 \mathrm{~kg}$ (média de $8,9 \mathrm{~kg}$ ) e na fêmeas de -0,3 a 16,5 kg (média de 9,8kg) em relação ao controle, o que corresponde também a aproximadamente $10 \%$ da média do ganho de peso observado pós-tratamento. Stromberg et al. (1997) e Ballweber et al. (2000) encontraram uma diferença de 15 e $20 \%$ no ganho de peso entre bezerros controle e tratados, mantidos em pasto separado e tratados duas e uma vez, respectivamente.

A percentagem alta de vacas parasitadas, com médias de OPG relativamente elevadas, observadas neste estudo, e em estudos anteriores no Brasil (Bianchin et al. 1987, Lima \& Guimarães 1992, Lima 1998) indicam que as vacas parecem ter um papel mais importante como fonte de contaminação das pastagens e de infecção dos bezerros durante a amamentação em climas tropicais e subtropicais, quando comparada com as percentagens menores de animais parasitados e OPG inferiores observadas em vacas de cria de gado de corte em climas temperados (Reinemeyer 1992, Suarez et al. 1992, Stromberg et al. 1997, Ballweber et al. 2000, Forbes et al. 2002). A maior contaminação da pastagem pelas vacas e temperaturas mais adequadas, durante todo o ano, para o desenvolvimento de larvas infectantes, possivelmente, explique a prevalência alta $(70-100 \%$, média de 83\%), e médias de OPG bastante elevadas (161- 410, média de 267) encontradas também nos bezerros aos 3 a 5 meses de idade.

Após a everminação dos bezerros houve uma correlação entre a prevalência e o OPG com o ganho de peso observado no desmame. $O$ grupo tratado com ivermectina de ação prolongada (Grupo A) tinha no desmame menos animais parasitados, 
média de OPG menores e ganharam mais peso que os animais do Grupo Controle (Grupo C). O grupo de animais tratados com ivermectina (Grupo B) tinha, no desmame, prevalência, média de OPG e ganho de peso intermediários (Quadros 6, 7 e 8).

No Brasil a everminação de vacas em sistema de gado de corte tem sido indicada no pré-parto (Bianchin et al. 1987, Lima \& Guimarães 1992, Lima 1998,) ou no pré-parto e 30 dias pósparto (Pereira 1983). A everminação no pré-parto é preconizada visando diminuir a contaminação das pastagens e, consequentemente, retardar e diminuir a infecção nos bezerros. No Brasil Central, durante todo o ano há condições para o desenvolvimento das larvas infectantes, e, possivelmente, como observado neste estudo uma única aplicação de anti-helmíntico no pré-parto seria insuficiente para manter as vacas com OPG negativos ou baixos até os bezerros completarem 2 ou mais meses de idade, quando o pasto passa a ser item importante em sua dieta. As contagens de OPG nas vacas, maiores de meados da lactação até o desmame, coincidentes com o aumento do OPG nos bezerros, indica a necessidade do tratamento das vacas concomitante com o tratamento dos bezerros aos 3 a 5 meses com o objetivo de diminuir a contaminação das pastagens e a reinfecção dos bezerros.

As vacas tratadas no pré-parto não tiveram diminuição do OPG e não perderam menos peso que as controle entre o parto e o desmame. $O$ tratamento das vacas no pré-parto também não diferenciou significativamente o peso dos bezerros aos 3 a 5 meses, mas as vacas tratadas e controle compartilharam a mesma invernada, uma dos das principais falhas de delineamento experimental apontadas por Reinemeyer (1992).

0 tratamento de bezerros por outro lado mostrou resultados benéficos. Os bezerros tratados com ivermectina de ação prolongada ganharam em média $6,9 \mathrm{~kg}(\mathrm{P}<0,0002)$ mais que os controle. Diferença, dessa magnitude ou maior, no ganho de peso com tratamento anti-helmíntico em bezerros lactentes tem sido verificada principalmente nos trabalhos em que os grupos tratados e controle não compartilharam a mesma invernada, embora com contagens de OPG no início do tratamento muito menores que as verificadas neste estudo (Aumont et al. 1991, Stromberg et al. 1997, Ballweber et al. 2000, Forbes et al. 2002). Portanto, é provável que, se os animais tratados não tivessem compartilhado a pastagem com as vacas/bezerros controles, essa diferença no ganho de peso fosse maior.

$O$ efeito do tratamento anti-helmíntico em bovinos após o desmame tem sido demonstrado e bem documentado em todos os continentes. Entretanto, o tratamento de vacas e de bezerros lactentes ainda suscita dúvidas, em parte devido a falhas no desenho experimental, como tamanho de amostras e repetição de tratamentos suficiente para determinar diferenças pequenas nos parâmetros de performance e, por mais pesquisas que defina o limiar econômico do parasitismo (Reinemeyer 1992).

Este estudo demonstrou que, nas condições ambientais do Brasil Central, o crescimento de bezerros antes do desmame pode ser prejudicado pelo parasitismo gastrintestinal subclinico, porém a recomendação de tratamento não pode ser generalizada para todos os sistemas produtivos. Surtos de diarréia como ocorreu em uma das propriedades, outras patologias ou nível nutricional que prejudique o crescimento dos animais, podem diminuir ou eliminar o ganho com a adoção desta prática. A prática é particularmente recomendada para sistemas de ciclo curto, com os animais entrando na fase de terminação após o desmame. Em sistemas de ciclo longo, ganhos compensatórios de peso pelos animais controle pode não compensar financeiramente a adoção da everminação de bezerros antes do desmame.

Agradecimentos.- Os autores agradecem a Fundação de Apoio ao Desenvolvimento do Ensino, Ciência e Tecnologia do Estado de Mato grosso do Sul (FUNDECT) pelo suporte financeiro. Aos proprietários Euclides Damiani Pedrinola e Arno Seemann pela permissão ao uso dos animais e ao Laboratorista Ananias Louveira e ao Técnico Agrícola Paulino Gauna Gomes pela colaboração nos trabalhos de campo e nas análises laboratoriais.

\section{REFERÊNCIAS}

Aumont G., Gauthier D., Coulaud G. \& Gruner L. 1991. Gastro-intestinal parasitism of cattle in native pasture grazing system in Guadalupe (French West Indies). Vet. Parasitol. 40(1-2):29-46.

Bianchin I., Honer M.R., Curvo, J.B.E. 1987. Produção de ovos de nematódeos gastrintestinais em vacas Nelore durante o período do periparto. Pesq. Agropec. Bras. 22(11/12):1239-1242.

Bianchin I., Honer M.R., Nunes S.G., Nascimento Y.A., Curvo J.B.E. \& Costa F.P. 1993. Epidemiologia dos nematódeos gastrintestinais em bovinos de corte nos cerrados e o controle estratégico no Brasil. Circular Técnica 24, Embrapa-CNPGC, Campo Grande, MS. 120p.

Ballweber L.R., Evans R.R., Siefker C., Johnson E.G., Rowland W.K., Zimmerman G.L., Thompson L., Wastrom D.J., Skogerboe T.L., Brake A.C. \& Karle, V.K. 2000. The effectiveness of doramectin pour-on in the control of gastrointestinal nematode infections in cow-calf herds. Vet. Parasitol. 90(1-2):93-102.

Catto J. B. 1989. Parasitismo por nematóides gastrintestinais em vacas de cria na região do Pantanal. Pesq. Agropec. Bras. 24(1):127-129.

Catto J.B. \& Furlong J. 1982. Desenvolvimento de bovinos criados extensivamente submetidos a vários esquemas de tratamento anti-helmíntico no Pantanal Mato-Grossense. Pesq. Agropec. Bras. 17(13):31-36.

Forbes A.B., Cutler K.L. \& Rice B.J. 2002. Subclinical parasitism in springborn, beef suckler calves: epidemiology and impact on growth performance during the first grazing season. Vet. Parasitol. 104(4):339-344.

Gordon H. Mcl. \& Whitlock H.V. 1939. A new technique for counting nematode eggs in sheep faeces. J. Counc. Sci. Ind. Res. 12(1):50-52.

Honer M.R \& Bianchin I. 1993. Programa de controle estratégico da verminose em gado de corte no Brasil. Hora Veterinária, Porto Alegre, 71:17-19.

Lima W.S. \& Guimarães, M.P. 1992. Comportamento das infecções helmínticas em vacas de rebanho de corte durante a gestação e lactação. Arq. Bras. Med. Vet. Zootec. 44(5):387-396.

Lima W.S. 1998. Seasonal infection pattern of gastrointestinal nematodes of beef cattle in Minas Gerais State, Brazil. Vet. Parasitol. 74(2-4):203-214.

Pereira N.A.W. 1983. Influência do período periparto na produção de ovos de nematódeos gastrintestinais em bovinos de corte. Dissertação de Mestrado, Univ. Fed. Rio Grande do Sul, Porto Alegre. 66p.

Reinemeyer C.R. 1992. The effects of anthelmintic treatment of beef cows on parasitologic and performance parameters. Comp. Contin. Educ. Prat. Vet. 14(5):678-686.

SAS 1998. User's guide: statistics. SAS Institute, Cary. 584p.

Stromberg B.E., Vatthauer R.J., Schlotthauer J.C., Myers G.H., Haggard D.L., King V.L. \& Hanke H. 1997. Production responses folowing strategic parasite control in a beef cow/calf herd. Vet. Parasitol. 68(4):315-322.

Suarez V.H., Busseti M.R. \& Fort M.C. 1992. Epidemiology and effects of nematode infections on beef cow-calf systems of Argentina's western pampas. Vet. Parasitol. 42(1-2):73-81.

Ward J.K., Ferguson D.L., Parkhurst A.M., Berthelsen J. \& Nelson M.J. 1991. Internal parasite levels and response to anthelmintic treatment by beef cows and calves. J. Anim. Sci. 69(3):917-922. 